\title{
Totally laparoscopic hepatectomy exposing the vessels around the tumor intended to secure the surgical margin
}

\author{
Goro Honda • Masanao Kurata $\cdot$ Yukihiro Okuda • \\ Shin Kobayashi $\cdot$ Katsunori Sakamoto
}

Received: 31 January 2013/ Accepted: 9 June 2013 / Published online: 3 January 2014

(c) The Author(s) 2013. This article is published with open access at Springerlink.com

\begin{abstract}
Anatomical hepatectomy (AH) is basically not required for metastatic tumors in terms of oncology, but is required for hepatocellular carcinoma [1-5]; however, the surgeon cannot secure the surgical margin by palpation via a laparoscopic approach. Therefore, AH or partial hepatectomy exposing the vessels around the tumor (PHev) is often better for deep-seated or invisible lesions [6, 7] because unexpected exposure of the tumor on the cutting plane can be avoided by creating a cutting plane on the side of exposed vessels. From August 2008 to December 2012, we performed totally laparoscopic $\mathrm{AH}$ or $\mathrm{PHev}$ for 29 patients ( $\mathrm{AH}$ in 21 patients and $\mathrm{PHev}$ in 8 patients) to secure the surgical margin of metastatic tumors [8, 9]. The median operative time was 329 (range 147-519) min, with median blood loss of 141 (range 5-430) g. Conversion was performed for one patient whose stump of the Glissonean branch was positive in a frozen section. Additional hepatectomy was performed via an open approach. Postoperative morbidity rate was $20.7 \%$ (peroneal palsy in two patients, ileus in one patient, biloma in one patient, and pulmonary embolism in one patient). Mortality was zero. The median length of hospital stay after surgery was 9 (range 4-21) days. Only one patient, who underwent extended posterior sectorectomy for a 4.2-cm tumor
\end{abstract}

Electronic supplementary material The online version of this article (doi:10.1007/s00464-013-3329-1) contains supplementary material, which is available to authorized users.

G. Honda $(\bowtie) \cdot$ M. Kurata · Y. Okuda · S. Kobayashi ·

K. Sakamoto

Department of Surgery, Tokyo Metropolitan Cancer and

Infectious Diseases Center, Komagome Hospital, 3-18-22

Honkomagome, Bunkyo-ku, Tokyo 113-8677, Japan

e-mail: ghon@cick.jp developing close to the right main Glissonean pedicle, had a microscopically positive margin, because the tumors were exposed on the cutting plane. The embedded video demonstrates hepatectomy of the dorsal half-segment of the right anterior sector, during which the liver was divided at the anterior fissure [10] and the border between the anterior and posterior sector. Totally laparoscopic hepatectomy exposing the vessels around the tumor can be performed safely and is useful to secure the surgical margin in patients with a metastatic tumor.

Keywords Laparoscopic hepatectomy · Anatomical hepatectomy · CUSA · Glissonean pedicle transection method

Disclosures Drs. Goro Honda, Masanao Kurata, Yukihiro Okuda, Shin Kobayashi and Katsunori Sakamoto have no conflicts of interest or financial ties to disclose.

Open Access This article is distributed under the terms of the Creative Commons Attribution License which permits any use, distribution, and reproduction in any medium, provided the original author(s) and the source are credited.

\section{References}

1. Kobayashi A, Miyagawa S, Miwa S, Nakata T (2008) Prognostic impact of anatomical resection on early and late intrahepatic recurrence in patients with hepatocellular carcinoma. J Hepatobiliary Pancreat Surg 15:515-521

2. Eguchi S, Kanematsu T, Arii S, Okazaki M, Okita K, Omata M, Ikai I, Kudo M, Kojiro M, Makuuchi M, Monden M, Matsuyama Y, Nakanuma Y, Takayasu K, Liver Cancer Study Group of Japan (2008) Comparison of the outcomes between an anatomical subsegmentectomy and a non-anatomical minor hepatectomy for 
single hepatocellular carcinomas based on a Japanese nationwide survey. Surgery 143:469-475

3. Yamamoto J, Kosuge T, Takayama T, Shimada K, Yamasaki S, Ozaki H, Yamaguchi N, Makuuchi M (1996) Recurrence of hepatocellular carcinoma after surgery. Br J Surg 83:1219-1222

4. Regimbeau JM, Kianmanesh R, Farges O, Dondero F, Sauvanet A, Belghiti J (2002) Extent of liver resection influences the outcome in patients with cirrhosis and small hepatocellular carcinoma. Surgery 131:311-317

5. Sakon M, Nagano H, Nakamori S, Dono K, Umeshita K, Murakami T, Nakamura H, Monden M (2002) Intrahepatic recurrences of hepatocellular carcinoma after hepatectomy: analysis based on tumor hemodynamics. Arch Surg 137:94-99

6. Han HS, Cho JY, Yoon YS (2009) Techniques for performing laparoscopic liver resection in various hepatic locations. J Hepatobiliary Pancreat Surg 16:427-432
7. Abu Hilal M, Di Fabio F, Abu Salameh M, Pearce NW (2012) Oncological efficiency analysis of laparoscopic liver resection for primary and metastatic cancer: a single-center UK experience. Arch Surg 147:42-48

8. Honda G, Kurata M, Okuda Y, Kobayashi S, Tadano S, Yamaguchi T, Matsumoto H, Nakano D, Takahashi K (2013) Totally laparoscopic hepatectomy exposing the major vessels. J Hepatobiliary Pancreat Sci 20:435-440

9. Okuda Y, Honda G, Kurata M, Kobayashi S (2013) A useful and convenient procedure for intermittent vascular occlusion in laparoscopic hepatectomy. Asian J Endosc Surg 6:100-103

10. Cho A, Okazumi S, Makino H, Miura F, Shuto K, Mochiduki R, Tohma T, Kudo H, Matsubara K, Gunji H, Yamamoto H, Ryu M, Ochiai T (2004) Anterior fissure of the right: the third door of the liver. J Hepatobiliary Pancreat Surg 11:390-396 